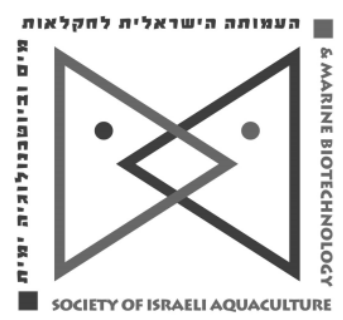

The IJA appears exclusively as a peer-reviewed on-line open-access journal at http://www.siamb.org.il. To read papers free of charge, please register online at registration form.

Sale of $I J A$ papers is strictly forbidden.

\title{
Yeast and Corn Flour Supplement to Enhance Large-scale Culture Efficiency of Marine Copepod Tisbe furcata, a Potential Live Food for Fish Larvae.
}

\author{
Kai Wang ${ }^{1}$, Kunming $\mathrm{Li}^{1}$, Junfeng Shao ${ }^{1}$, Wenjing $\mathrm{Hu}^{1}$, Min $\mathrm{Li}^{1}$, \\ Wen Yang ${ }^{1}$, Jiteng Tian ${ }^{2}$, Qiang Lin ${ }^{3 *}$ \\ ${ }^{1}$ School of Agriculture, Ludong University, Yantai 264025, China \\ ${ }^{2}$ Key Laboratory for Sustainable Utilization of Marine Fisheries Resources, \\ Ministry of Agriculture, Yellow Sea Fisheries Research Institute, Chinese \\ Academy of Fishery Sciences, Qingdao 266071, China \\ ${ }^{3}$ CAS Key Laboratory of Tropical Marine Bio-resources and Ecology, South \\ China Sea Institute of Oceanology, Chinese Academy of Sciences, \\ Guangzhou 510301, China
}

Keywords: Tisbe furcata; copepods; yeast; corn flour; large-scale culture

\begin{abstract}
Copepods can generally provide balanced nutrition for first-feeding of fish larvae, and Tisbe furcata is recognized as a potential larval diet for aquaculture. In this study we examined the effects of feed composition and water quality on the population density of $T$. furcata over 20 days in large-scale culture. Results showed that the population density of $T$. furcata increased when fed a diet supplemented with yeast and corn flour $(P<0.05)$ and reached a greater mass compared to three other diet compositions. During culture, nitrite and phosphate concentrations in the water were positively correlated with the population density of $T$. furcata. The concentration levels of nitrate and ammonia nitrogen were low, and did not reveal any negative effects on the growth of $T$. furcata. We found that the feed formula that contained yeast and corn flour in given quantities did affect the quality of water, even in high culture densities. Yeast and corn flour could constitute promising candidates for feed supplements for T. furcata, or other copepod species in the future.
\end{abstract}

* Corresponding author: Kai Wang. email: wangkyt@163.com 


\section{Introduction}

Diets and nutrients can affect survival and growth rates of farmed fish. Copepods are sometimes used as a larval diet for fish (Drillet et al. 2006; Rasdi and Qin 2014). Copepods can generally provide more balanced nutrition for first-feeding fish larvae, compared to diets consisting solely of rotifers and artemia (Watanabe et al. 1983; Shields et al. 1999). Previous reports show that rotifers and artemia lack some essential nutrients, especially essential fatty acids, e.g., eicosapentaenoic acid (EPA, C20:5n-3), docosahexaenoic acid (DHA, C22:6n-3) and arachidonic acid (ARA, 20:4n-6), which are required by most fish larvae (Drillet et al. 2006; Rajkumar and Vasagam 2006). Consequently, diets comprised only of rotifers and artemia are often enriched by polyunsaturated fatty acid (PUFA) before being fed to fish larvae (Rasdi and Qin 2014). In contrast, copepods contain a high proportion of polar lipids (Ajiboye et al. 2011) and exogenous digestive enzymes that can contribute to fish larvae digestion (Zaleha et al. 2012). In addition, they are also natural sources of antioxidants, astaxanthin, and vitamins C and E (Barroso et al. 2013). Therefore, copepods constitute an important candidate for marine fish larviculture (Rasdi and Qin 2014).

The main source of copepods for most farmers is the ocean and many culture methods for copepods have been reported in the past few years from the World Copepod Culture Database (Drillet et al., 2011). In fact, there are over 60 copepod species that have been successfully raised in laboratory conditions (Mauchline 1998), and almost 30 culture methods have been referenced (Støttrup 2003; Lee et al. 2005). Cost-effective protocols for the mass culture of copepods are still to be developed (Ajiboye et al. 2011) since low production, long generation time, seasonal variations of yields, and high costs, constitute major inherent problems related to culture of copepods (Støttrup 2000; Conceição et al. 2009; Ajiboye et al. 2011).

T. furcata are widely distributed salong the coast. They have small body size (Zhao et al. 2011), short generation time (Bergmans 1981), and high proportion of EPA and DHA (Parrish et al. 2012). They have been experimentally fed to fish larvae, and these larvae are known to have significantly higher survival and growth rates compared to fish fed other diets (Bai 2014). Currently, wild $T$. furcata have been widely used as a cost effective diet by farmers on the coastline of the North of China (Wang et al. 2015). Considering that $T$. furcata may constitute an important diet for marine fish larvae, the present study aimed to elucidate feed composition on their population density during 20 $\mathrm{d}$ of mass culture. In addition we investigated variations of nitrite, nitrate, ammonia nitrogen, and phosphate concentrations with changes of the population under different feed supply conditions.

\section{Materials and Methods}

Copepods. T. furcata used in this experiment were collected from Muping Beach,

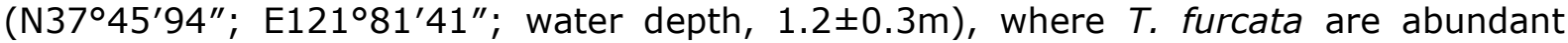
compared with other copepod species. They were temporarily cultured in the laboratory in circular tanks (radius $=40 \mathrm{~cm}$, depth $=120 \mathrm{~cm}$ ) and fed with Nannochloropsis oculata $\left(1-2 \times 10^{8} / \mathrm{ml}\right.$, Yantai Hairong Microalgae Breeding Co., Ltd.) twice a day until they reached a density of approximately 5000 inds/L. The water In the tanks was fresh seawater filtered twice through a sand filter. was used. Throughout the experiment temperature, salinity, $\mathrm{DO}$, and $\mathrm{pH}$ were maintained at $22 \pm 1.0^{\circ} \mathrm{C}, 31 \pm 2.0 \%, 6.2 \pm 0.3$ $\mathrm{mg} / \mathrm{L}$, and $7.8 \pm 0.3$ respectively as recommended (Bai 2014). Light intensity of the water surface in each tank was uniform (approximately 1500-1600 lux) and photoperiod was $8 \mathrm{~h}: 16 \mathrm{~h}(\mathrm{D}: \mathrm{L})$.

Treatments. Four treatments, W, $2 \mathrm{~W}, \mathrm{Y}$, and J formulas respectively were used to test the effects of different food composition on $T$. furcate population density during $20 \mathrm{~d}$ of mass culture (see Table 1 and Figure 1 ). Six concrete indoor ponds with a water depth of $0.8 \mathrm{~m}(5 \mathrm{~m} \times 3.6 \mathrm{~m} \times 1.2 \mathrm{~m})$ were used in six replicates for each treatment. Fresh seawater was supplied into these 24 concrete ponds for $2 \mathrm{~d}$ prior to onset of the experiment. At the beginning of the experiment, $T$. furcata were transferred to the concrete ponds at a density of $30 \pm 4$ inds/L. 
Table 1. Proximate composition of different mixed feeds for mass culture of Tisbe furcata ${ }^{a}$

\begin{tabular}{|c|c|c|c|c|c|c|c|}
\hline \multirow[b]{2}{*}{ Formula } & \multicolumn{6}{|c|}{ Components ( $g$ or $\mathrm{ml} /$ pond) } & \multirow[b]{2}{*}{ Total amount } \\
\hline & $\begin{array}{l}\text { sargasso } \\
\text { powder }\end{array}$ & $\begin{array}{l}\text { scallop edge } \\
\text { powder }\end{array}$ & $\begin{array}{l}\text { sea cucumber } \\
\text { compound } \\
\text { feed }\end{array}$ & corn flour & $\begin{array}{l}\text { active } \\
\text { dry yeast }\end{array}$ & algae fluid & \\
\hline W & $175 \pm 3 g$ & $175 \pm 3 g$ & $150 \pm 3 g$ & 0 & 0 & $50 \pm 0.3 \mathrm{ml}$ & $500 \mathrm{~g}+50 \mathrm{ml}$ \\
\hline $2 W$ & $350 \pm 5 g$ & $350 \pm 5 g$ & $300 \pm 5 g$ & 0 & 0 & $50 \pm 0.3 \mathrm{ml}$ & $500 \mathrm{~g}+50 \mathrm{ml}$ \\
\hline$Y$ & $150 \pm 2 g$ & $150 \pm 2 g$ & $100 \pm 2 g$ & $100 \pm 2 g$ & 0 & $50 \pm 0.3 \mathrm{ml}$ & $500 \mathrm{~g}+50 \mathrm{ml}$ \\
\hline J & $150 \pm 3 g$ & $150 \pm 3 g$ & $100 \pm 2 g$ & $100 \pm 2 g$ & $50 \pm 1 \mathrm{~g}$ & $50 \pm 0.3 \mathrm{ml}$ & $500 \mathrm{~g}+50 \mathrm{ml}$ \\
\hline
\end{tabular}

${ }^{a} \mathrm{~W}$ refers to the basic formula (Wang et al. 2015); $2 \mathrm{~W}$ doubles the amount of all other components of $\mathrm{W}$ except for algae fluid; $\mathrm{Y}$ substitutes partial amount of the basic formula for corn flour without changing the total amount. J adds extra $50 \mathrm{~g}$ active dry yeast into the formula $Y$, and is pretreated by fermentation for two days before use. Apart from the algae, fluid is used once a week; other components are used every other day.

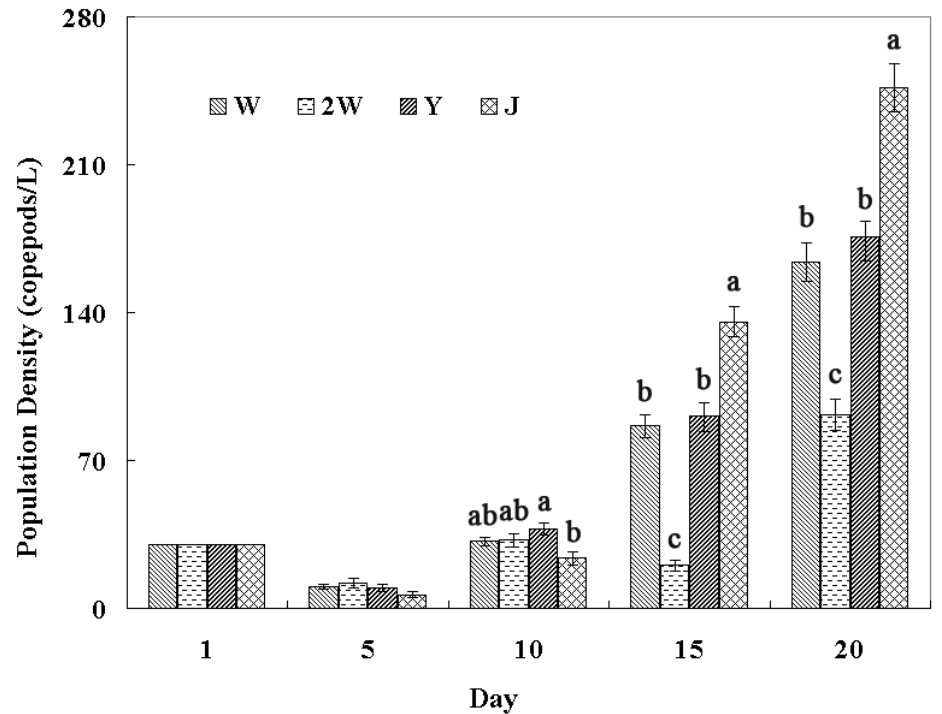

Fig.1. Effects of different mixed feeds on population density of Tisbe furcata.

$\mathrm{W}$ represents the basic formula and dosage of mixed feeds containing sargasso powder, edge powder, sea cucumber compound feed and algae fluid.

$2 \mathrm{~W}$ is the same as $\mathrm{W}$, but the dosage of $2 \mathrm{~W}$ is twice as much as $\mathrm{W}$.

$Y$ represents the mixed feed, corn flour is added accordingly reducing the proportion of sargasso powder, edge powder, and cucumber compound feed, without changing the total dosage.

In $J, 50 \mathrm{~g}$ active dry yeast is added into $Y$, and then $\mathrm{J}$ is pretreated by fermentation for 2 days before use. There are six replicates for each treatment. Data are means \pm SE. Different letters indicate significant differences $(P<0.05)$.

Feed for all treatments was mixed with $5 \mathrm{~L}$ of water, and then fed to the copepods at 08:00 every $2^{\text {nd }}$ day. During the first 10 days of culture, the quantity of feed per tank was given as presented in Table 1 and doubled during the last $10 \mathrm{~d}$

Count. The population density of $T$. furcata was measured in each pond every day throughout the experiment. Five liters of culture water was sampled from four corners and the center of the pond. One liter of water was taken from $30 \mathrm{~cm}$ depth and another from the surface of each tank. All the water samples were filtered through a 100 mesh $(0.15 \mathrm{~mm})$ net to collect, count, and record all copepods in each sample. Two liters of filtered water from each pond was used to determine the nitrite, nitrate, ammonia nitrogen, and phosphate concentrations which were measured every day according to the Specifications for Oceanographic Survey-Part 4 (SCPSW, 2007) and the modified method by Wang et al. (Wang et al., 2015).

Data analysis. Statistical analysis was performed with SPSS 11.5 software package (SPSS Inc., U.S.A.). Effect of different feeds on the population density of copepods was analyzed with a one-way ANOVA followed by LSD test at $P<0.05$. The relationship between each water nutrient element and the population density of copepods was assessed by Pearson's correlation analysis. 


\section{Results}

Effect of different feeds on the population density of $T$. furcata. The population densities of $T$. furcata on day 5 were lower than on day 1 in all groups (Fig. 2). A small difference in the population densities of $T$. furcata among the four treatments occurred on day 10 $(P<0.05)$, and increased on day 15 and day 20 . The final density of $T$. furcata in the J treatment reached a peak of 246 copepods/L on day 20 and was significantly higher than the density of the other three treatments $(P<0.05)$. T. furcata density in the $2 \mathrm{~W}$ treatment was the lowest.

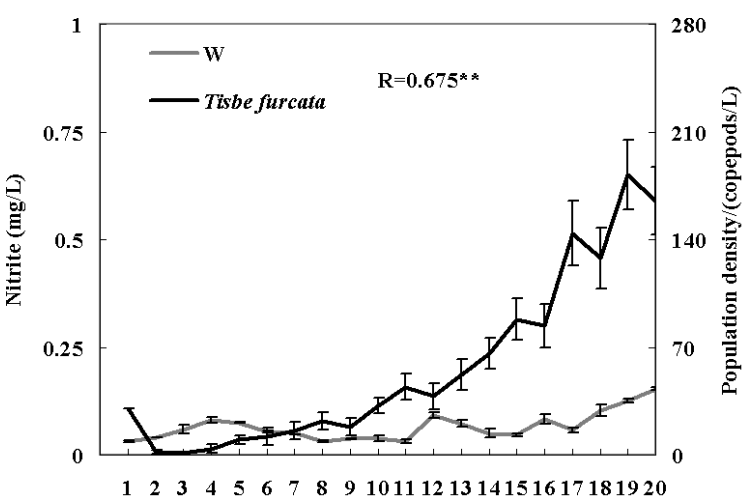

Day

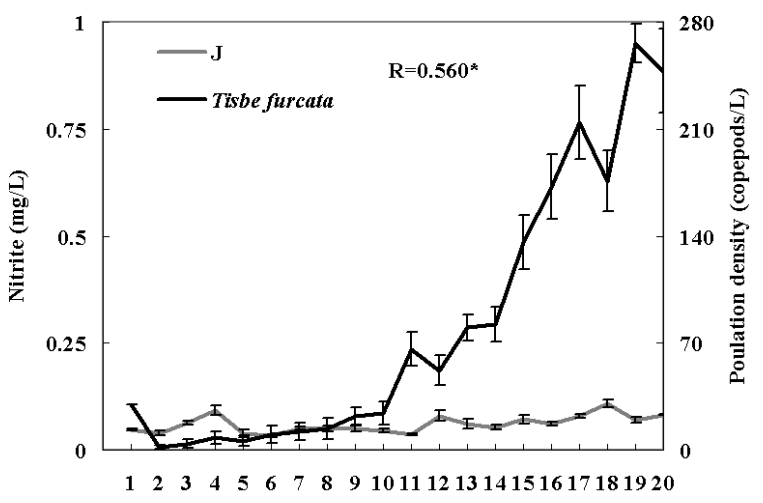

Day

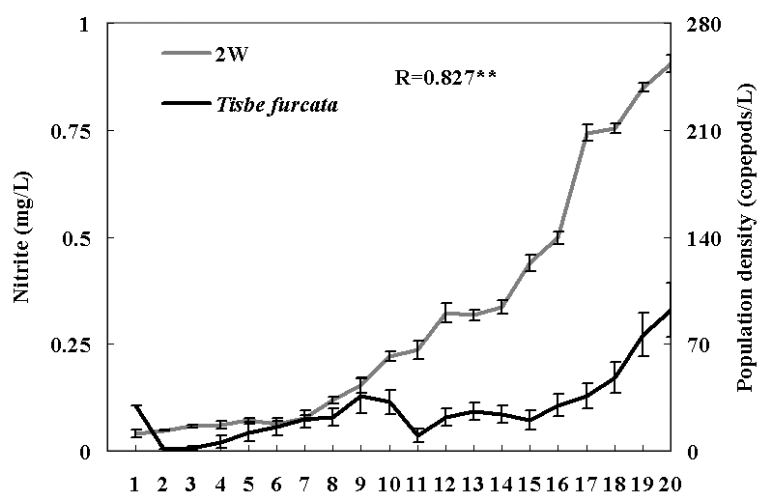

Day

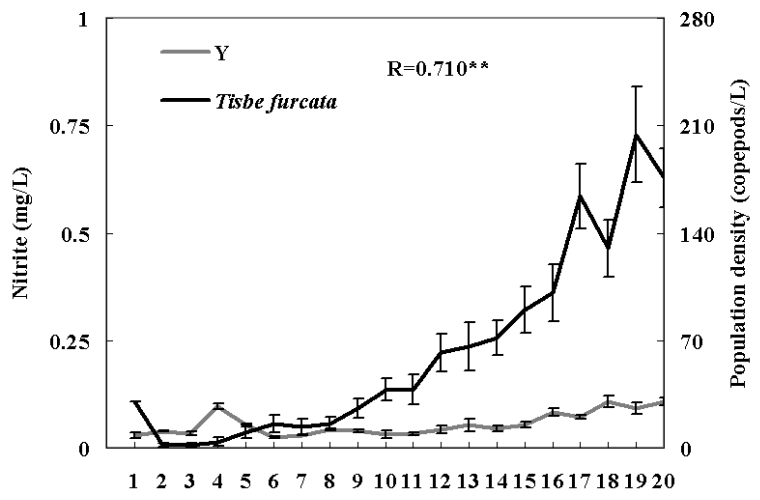

Day

Fig. 2. Correlation between population density of Tisbe furcata and concentrations of nitrite with the four experimental mixed feeds was investigated using Pearson's correlation analysis.

* indicates that the correlation is significant at the 0.05 level.

** indicates that the correlation is significant at the 0.01 level.

Correlation between nitrite, nitrate, ammonia nitrogen, phosphate, and copepod population. The correlation between nitrite concentration and population density of $T$. furcata of all feeds is shown in Figure 2. The nitrite concentration was significantly positively related with the population density of $T$. furcata in all groups. During the culture cycle, the nitrite concentration in $\mathrm{W}, \mathrm{Y}$ and $\mathrm{J}$ increased slightly, but at a much slower pace and was never higher than $0.16 \mathrm{mg} / \mathrm{L}$, while in $2 \mathrm{~W}$, it increased rapidly and reached a final concentration about $0.9 \mathrm{mg} / \mathrm{L}$.

As shown in Figure 3, the nitrate concentration was positively correlated with the population density of $T$. furcata in both $2 \mathrm{~W}$ and $\mathrm{J}$ but, there was no such relationship in $\mathrm{W}$ and $Y$ diets. The nitrate concentrations in four research groups fluctuated during the culture cycle but never exceeded $1.2 \mathrm{mg} / \mathrm{L}$. 


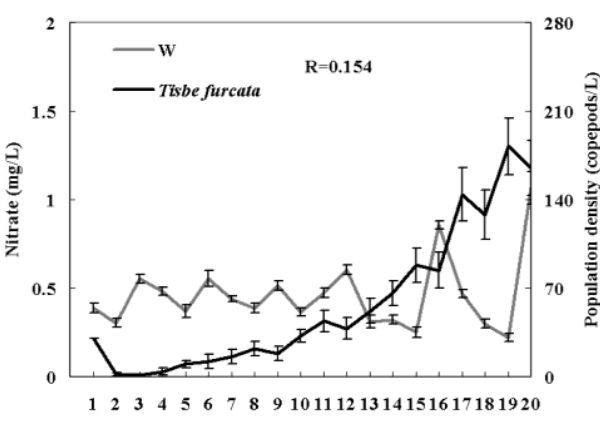

Day

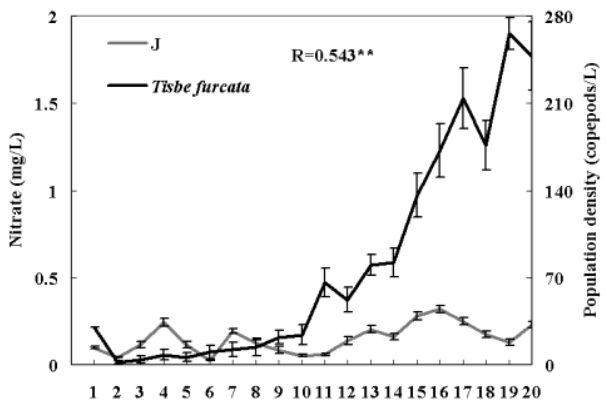

Day

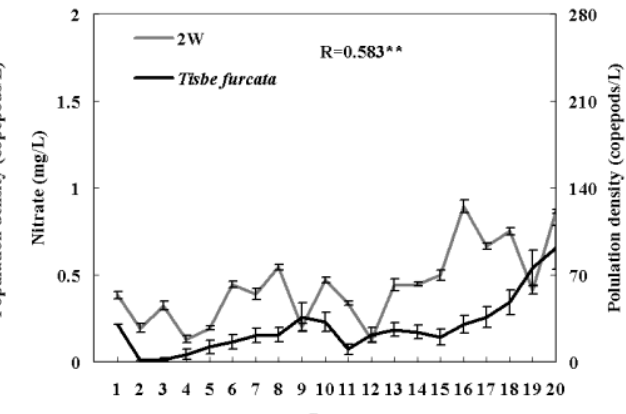

Day

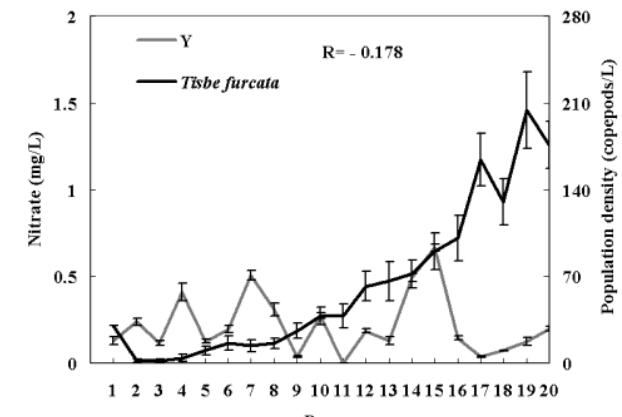

Day

Fig.3. Correlation between population density of Tisbe furcata and concentration of dissolved nitrate, by feeding with four different mixed feeds were investigated by Pearson's correlation analysis.

* indicates that the correlation is significant at the 0.05 level.

** indicates that the correlation is significant at the 0.01 level.

There was no significant correlation between the concentration of ammonia nitrogen and population density of $T$. furcata (Fig. 4). There were large fluctuations in concentration of ammonia nitrogen in all groups during the culture cycle, but its maximum value did not exceed $0.19 \mathrm{mg} / \mathrm{L}$.
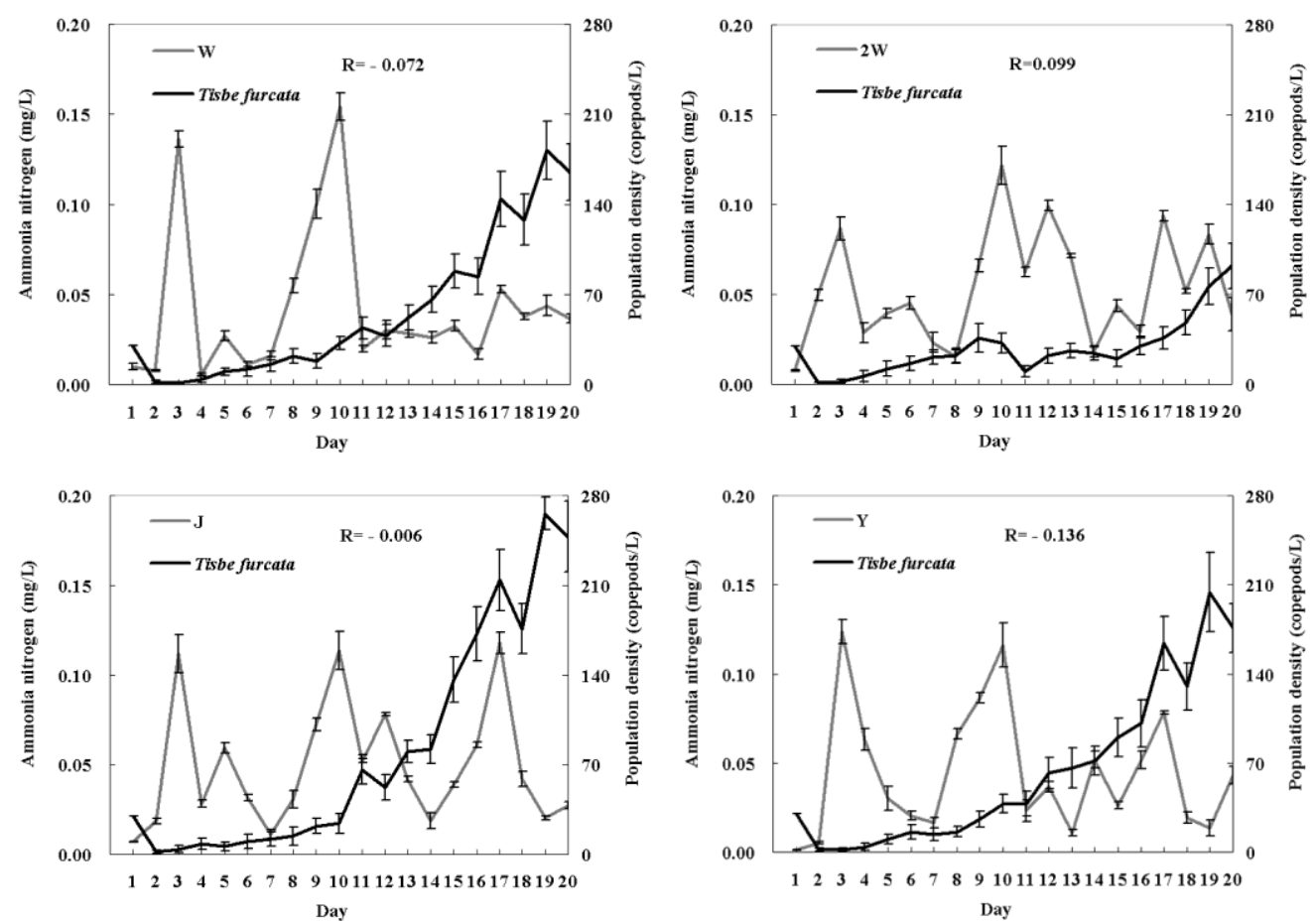

Fig.4. Correlations between population density of Tisbe furcata and concentrations of water chemical element ammonia nitrogen, by feeding with four different mixed feeds were investigated by Pearson's correlation analysis. * means the correlation is significant at the 0.05 level. ** means the correlation is significant at the 0.01 level. 
The concentration of phosphate gradually increased during the culture cycle, and correlated positively with the population density of $T$. furcata in all investigated groups (Fig. 5). Maximum values of the concentrations in all groups occurred on day 20 and ranged from $0.95-1.14 \mathrm{mg} / \mathrm{L}$.
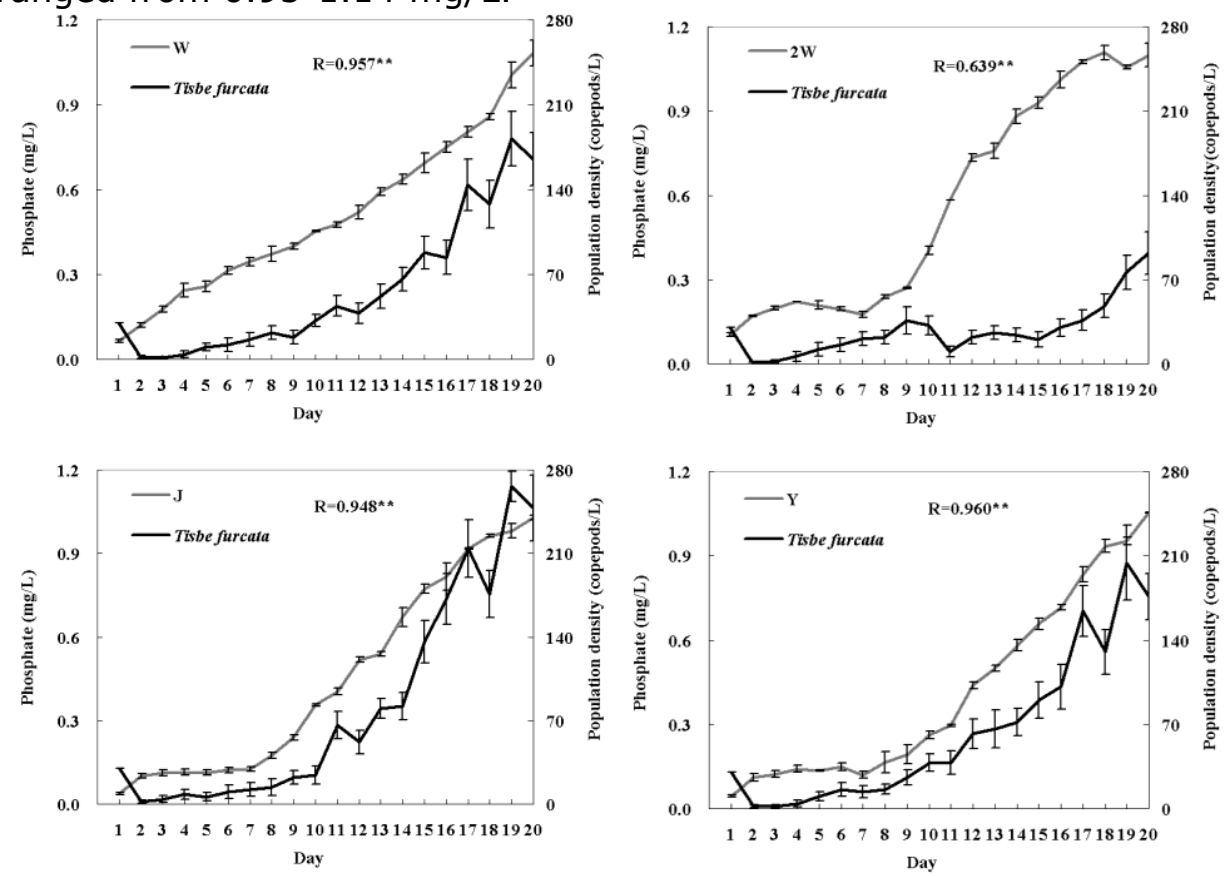

Fig.5. Correlations between population density of Tisbe furcata and concentration of phosphate water chemical elements when four different mixed feeds were investigated using Pearson's correlation analysis. *indicates significant correlation at the 0.05 level. **indicates significant correlation at the 0.01 level.

Diet $\mathrm{J}$ had the best effects on population density of $T$. furcata, followed by $\mathrm{Y}, \mathrm{W}$ and $2 \mathrm{~W}$. The concentration of nitrite and phosphate were significantly correlated with the population density of $T$. furcata in all groups, while the concentrations of nitrate and ammonia nitrogen were not.

\section{Discussion}

Harpacticoid copepod species are often considered most suitable for mass production (Ajiboye et al., 2011). There are different methods of large scale mass culture of several Tisbe spp. (Ajiboye et al., 2011). However these large scale cultures were not sufficiently cost-effective to meet the needs of the aquaculture industry. There is a need for inexpensive food to lower the cost of copepod productions (Drillet et al., 2011). T. furcata fed a sea cucumber compound together with sargasso and scallop skirt powder has been tested (Wang et al. 2015). The present study revealed that $T$. furcata exhibited better growth and reproduction rates when yeast and corn flour were supplemented to the sea cucumber saragosso compound feed, and scallop skirt powder (Fig. 1 and Table 1). Fermentation treatment and size optimization may make mixed feeds easier for ingestion and digestion thereby increasing growth and reproduction rates. Microalgae are also important for copepods in the wild, and can supply DHA and EPA to marine organisms (Parrish et al. 2012). This study is the first to report the use of corn flour for mass culture of copepods. Due to its high concentration of protein (approximately $28 \%$ ), fat $(9 \%-13 \%)$ and phosphorus $(0.94 \%-1.21 \%)$ products derived after fermentation, such as distiller's dried grains with solubles (DDGS), have enhanced growth of fish and shrimp (Cheng et al. 2003) (Zhao, 2009). The decrease in the population density at day 5 in all treatments might be the result of transfer and/or changes of culture environments, a phenomenon which occurs in other copepod species (Chen et al. 2006). Only copepods in the body of water (not the epibenthic T. furcata at the bottom of the tanks) were counted 
in order to avoid interfering with the experimental process. The actual population density would have been much higher if those had been included.

Identifying the prominent factors regulating the population dynamics of copepods is essential when using them as live food for aquaculture (Rasdi and Qin 2014). The relationship between copepod population density and four water chemical elements were consistent with results from our previous study which showed that concentration of nitrite was positively correlated with population density of copepods (Wang et al., 2015). In the present study, concentration of nitrite in the $2 \mathrm{~W}$ treatment was more than two times the recommended value $(0.4 \mathrm{mg} / \mathrm{L})$ for common growth of copepods (Wang et al. 2015). This may be one of the reasons that $T$. furcata had the lowest population density in the $2 \mathrm{~W}$ treatment. This result is consistent with other reports (Dong and Dai 2011). Nitrate, at normal pH levels causes no harm to aquatic livestock (Zhang et al., 2014). The concentration of ammonia nitrogen in all groups was far below the toxic concentration for copepods (Lu 2014). This could explain the lack of a correlation between the concentration of ammonia nitrogen and copepod population density (Fig. 4). Fastgrowing copepod species may exhibit a high demand for phosphorus (Rasdi and Qin 2014) which is the main component of the exoskeleton, and has positive effects on the growth of crustaceans (Vrede et al. 1999) (Fig. 5).

In conclusion, in the present study high population densities of $T$. furcata were achieved by supplementing feeds with yeast and corn flour without negatively affecting the environment in the experimental tanks. We therefore conclude that supplementing feeds for $T$. furcata with yeast and corn flour is recommended.

\section{Acknowledgements}

This study was funded by the Outstanding Youth Foundation in Guangdong Province (S2013050014802), the Development of Special Biology Industry in Shenzhen City (HY20130205001), and the Yantai Foundation for Development of Science and Technology (2016YT06000174) and the Science Foundation of Ludong University (LY2014042).

\section{References}

Ajiboye, O. O., A. F. Yakubu, T. E. Adams, E. D. Olaji, and N. A. Nwogu. 2011. A review of the use of copepods in marine fish larviculture. Rev Fish Biol Fish., 21(2):225246.

Bai, X. F. 2014. Choice and Cultivation of the first feeds of seahorse larval. Life Science. Ludong University, Yan Tai.

Barroso, M. V., C. V. A. de Carvalho, R. Antoniassi, and V. R. Cerqueira. 2013. Use of the copepod Acartia tonsa as the first live food for larvae of the fat snook Centropomus parallelus. Aquaculture, 388-391:153-158.

Bergmans, M. 1981. A demographic study of the life cycle of Tisbe furcata (BAIRD, 1837) (Copepoda, Harpacticoida). J Mar Biol Association UK, 61(3):691-705.

Chen, Q. X., J. Q. Sheng, Q. L, Y. L. G, J. Y. Lu. 2006. Effect of salinity on reproduction and survival of Pseudodiaptomus annandalei Sewell, 1919. Aquaculture, 258:575-582.

Cheng, Z. J., R. W. Hardy, and M. Blair. 2003. Effects of supplementing methionine hydroxyl analogue in soybean meal and distiller's dried grain-based diets on the performance and nutrient retention of rainbow trout (Oncorhynchus mykiss). Aquacult Res., 34(14): 1301-1310.

Conceição, L. E. C., M. Yúfera, P. Makridis, S. Morais, and T. M. Dinis. 2009. Live feeds for early stages of fish rearing. Aquaculture Research, 41:613-640.

Dong, Y. B., and Y. Y. Dai. 2011. Research survey of toxic effects of nitrite to aquatic animals. J Aquacult., 32(4):28-32.

Drillet, G., N. O. G. Jørgensen, T. F. Sørensen, H. Ramløv, and B. W. Hansen. 2006. Biochemical and technical observations supporting the use of copepods as live feed organisms in marine larviculture. Aquacult Res., 37(8):756-772. 
Drillet, G., S. Frouël, M. H. Sichlau, P. M. Jepsen, J. K. Højgaard, A. K. Joarder, and B. W. Hansen. 2011. Status and recommendations on marine copepod cultivation for use as live feed. Aquaculture, 315(3-4):155-166.

Lee, C. S., P. J. O'Bryen, and N. H. Marcus. 2005. Copepods in aquaculture. Blackwell, Oxford, $269 \mathrm{pp}$.

Lu, M. X. 2014. Toxicology effects of ammonia on two marine copepods species and summer marine water quality criteria for ammonia. College of Marine Life. Ocean University of China, Qing Dao.

Mauchline, J. 1998. The Biology of Calanoid Copepods. Adv Mar Biol., 33:1-660.

Parrish, C. C., V. M. French, and M. J. Whiticar. 2012. Lipid class and fatty acid composition of copepods (Calanus finmarchicus, C. glacialis, Pseudocalanus sp., Tisbe furcata and Nitokra lacustris) fed various combinations of autotrophic and heterotrophic protists. J Plankton Res., 34(5):356-375.

Rajkumar, M., and K. P. K. Vasagam. 2006. Suitability of the copepod, Acartia clausi as a live feed for Seabass larvae (Lates calcarifer Bloch): Compared to traditional livefood organisms with special emphasis on the nutritional value. Aquaculture, 261(2):649658.

Rasdi, N. W., and J. G. Qin. 2014. Improvement of copepod nutritional quality as live food for aquaculture: a review. Aquacult Res., 47(1):1-20.

Shields, R. J., J. G. Bell, F. S. Luizi, B. Gara, N. R. Bromage, and J. R. Sargent. 1999. Natural copepods are superior to enriched artemia nauplii as feed for halibut larvae (Hippoglossus hippoglossus) in terms of survival, pigmentation and retinal morphology: relation to dietary essential fatty acids. J Nutr., 129(6):1186-1194.

Støttrup, J. G. 2000. The elusive copepods: their production and suitability in marine aquaculture. Aquacult Res., 31(31):703-711.

Støttrup, J. G. 2003. Production and nutritional value of copepods. In: Støttrup JG, McEvoy LA (eds) Live feeds in marine aquaculture. Blackwell, Oxford, 318pp.

Vrede, T., T. Andersen, and D. O. Hessen. 2007. Phosphorus distribution in three crustacean zooplankton species. Limnol Oceanogr., 44(1):225-229.

Wang, K., K. M. Li, W. Yang, M. Li, D. L. Lü, and Q. Lin. 2015. Effects of water chemical elements on population density of Tisbe furcata and Paracalanus parvus under indoor breeding conditions. Ecol Sci., 34(6):105-110.

Watanabe, T., C. Kitajima, and S. Fujita. 1983. Nutritional values of live organisms used in Japan for mass propagation of fish: A review. Aquaculture, 34(1-2):115-143.

Zaleha, K., B. Ibrahim, B. A. John, and B. Y. Kamaruzzaman. 2012. Generation Time of Some Marine Harpacticoid Species in Laboratory Condition. J Biol Sci., $12(8): 433-437$.

Zhang, X. X., S. S. Li, Y. K. Hu, K. Jiang, and C. Shao. 2014. Toxicity effects of nitrite to aquatic animal. Journal of Anhui Agricultural Sciences, 42:1398-1400.

Zhao, W. X. 2009. Research of Distiller's Dried Grains with Soluble from corn and its application in the aquaculture feeds. Modern Fisheries Information, 24:12-14.

Zhao, W., X. W. Yin, and J. GAO. 2011. The morphology and development feature of copepod Tisbe furcata. J DaLian Ocean University, 26(6):475-483. 